Article

\title{
Progressive Decline of Partial Pressure of Carbon dioxide and Bicarbonate levels in Arterial Blood of Pregnant Women
}

\author{
Sunyal DK' ${ }^{1}$ Amin $\mathrm{MR}^{2}$, Molla MH', Talukder MAM${ }^{4}$, Ahmed A ${ }^{5}$ Begum $\mathbf{M}^{6}$
}

In the present study the partial pressure of carbon dioxide $\left(\mathrm{PaCO}_{2}\right)$ and bicarbonate ion $\left(\mathrm{HCO}_{3}^{-}\right)$in arterial blood was estimated in 32 women in Dhaka city. For this purpose a total 32 women subjects with age ranged from 25 years to 35 years without any recent history of respiratory diseases were selected and divided into 8 healthy non-pregnant women as control and 24 normal pregnant women as experimental group. Experimental group was further divided into 8 first trimester, 8 second trimester $\& 8$ third trimester of pregnant women. The $\mathrm{PaCO}_{2}$ and $\mathrm{HCO}_{3}{ }^{-}$were estimated by using "Easy Blood Gas Auto Analyzer”. The $\mathrm{PaCO}_{2}$ and $\mathrm{HCO}_{3}{ }^{-}$were estimated during the 1st, 2nd, 3rd trimesters of pregnant women and non-pregnant women. The mean of measured values of $\mathrm{PaCO}_{2}$ and $\mathrm{HCO}_{3}{ }^{-}$were analyzed statistically in relation to 1st, 2nd, 3rd trimesters of pregnant women \& non-pregnant women.

The $\mathrm{PaCO}_{2}$ and $\mathrm{HCO}_{3}{ }^{-}$were significantly lower in 1st trimester, 2nd trimester \& 3rd trimester of pregnant women than that of non-pregnant women. There were no statistically significant difference of $\mathrm{PaCO}_{2}$ and $\mathrm{HCO}_{3}{ }^{-}$between the 1st trimester and 2nd trimester ; between the 1st trimester and 3rd trimester ; and between the 2nd trimester and 3rd trimester of pregnant women.

It may be concluded that the causes of progressively decreased $\mathrm{PaCO}_{2}$ and $\mathrm{HCO}_{3}{ }^{-}$throughout the pregnancy were most likely to be due to effect of progesterone causing hyperventilation. Hyperventilation in pregnancy is due to hypersensitivity of respiratory centre. Due to hyperventilation, there is expelling out $\mathrm{CO}_{2} \& \mathrm{HCO}_{3}{ }^{-}$causing decreases $\mathrm{PaCO}_{2}$ \& $\mathrm{HCO}_{3}{ }^{-}$during pregnancy.

J Bangladesh Soc Physiol.2008 Dec;(3):13-16.

For author affiliations, see end of text. http://www.banglajol.info/index.php/JBSP

\section{Introduction}

$\mathbf{I}$ normal pregnancy, respiratory minute volume increases and hyperventilation of pregnancy occurs, which decrease in alveolar $\mathrm{CO}_{2}$. This decrease in alveolar $\mathrm{CO}_{2}$ lowers the maternal blood $\mathrm{CO}_{2}$ tension. Maternal hyperventilation is probably due to the action of progesterone on the respiratory center ${ }^{1}$. Metabolic changes occuring in pregnant women might modify pulmonary functions. Hypocapnia was observed during pregnancy and this was known to increase airway resistance. However, hormone-determined changes in smooth muscle tone \& possibly connective tissue elastance might

J Bangladesh Soc Physiol. 2008 Dec;(3):13-16. occur during pregnancy \& so could possibly after the mechanical properties of the respiratory system ${ }^{2}$.

Maternal ventilation \& blood gases undergo substantial change in pregnancy. There was a $40 \%$ increased in minute ventilation, resulting in a fall in $\mathrm{PaCO}_{2} \&$ bicarbonate ion. This increased ventilation is thought to be mediated by progesterone, which lowers the threshold of respiratory centre $\&$ increases the sensitivity of the respiratory centre. $\mathrm{PaCO}_{2}$ was lower in pregnant women at sea level compared with the non-pregnant women as control. 


\section{Article}

Pregnancy was associated with an increase in ventilation ; consequently, the arterial pressure of carbon dioxide falls ${ }^{4}$. During pregnancy hyperventilation caused the arterial carbon dioxide $\left(\mathrm{PaCO}_{2}\right)$ to fall, a compensatory fall in serum bicarbonate ion ${ }^{5}$.

So, it was important to observe the $\mathrm{PaCO}_{2}$ \& bicarbonate ion $\left(\mathrm{HCO}_{3}{ }^{-}\right)$in pregnant women both Physiologically and clinically. Although this type of work have been done in different countries by different workers but no established data is available in our country on this aspect.

Therefore, the aim and objective of this study to observe the changes in $\mathrm{PaCO}_{2}$ \& bicarbonate ion $\left(\mathrm{HCO}_{3}{ }^{-}\right)$during the different trimesters of normal pregnant women \& healthy non-pregnant women

\section{Methods}

$\mathrm{PaCO}_{2}$ and $\mathrm{HCO}_{3}{ }^{-}$were measured in normal pregnant and healthy non-pregnant women. For this purpose, total number of 32 subjects in which 8 non-pregnant as control and 24 pregnant women as experimental group with age ranged from 25 years to 35 years were selected. Experimental group was further divided into 8 first trimester, 8 second trimester, 8 third trimester of pregnant women. All the subjects were taken from different areas of Dhaka city that belonged to lower middle and poor socioeconomic classes.

The subjects were selected by carefully history taking and physical examination which revealed no evidence of past or recent significant respiratory diseases.

The measurement of $\mathrm{PaCO}_{2}$ and $\mathrm{HCO}_{3}{ }^{-}$were done both in healthy non-pregnant women and normal pregnant women during 1st trimester, 2nd trimester, 3rd trimester.

The $\mathrm{PaCO}_{2}$ and $\mathrm{HCO}_{3}{ }^{-}$were measured by Easy Blood Gas Auto Analyzer. The mean of measured values of $\mathrm{PaCO}_{2}$ and $\mathrm{HCO}_{3}{ }^{-}$were statistical analysis by unpaired Student's " $t$ " test between and among the study group. $\mathrm{P}$ value $<0.05$ was accepted as significance.
Partial pressure of carbon dioxide and bicarbonate

\section{Results}

The mean $\left( \pm \mathrm{SD}\right.$ ) of measured values of $\mathrm{PaCO}_{2}$ were $36.89 \pm 3.70,32.73 \pm 3.16,32.46 \pm 3.61$ and $31.03 \pm 3.20$ in non-pregnant women (control) and in pregnant women during 1st trimester, 2nd trimester \& 3rd trimester shown in tableI. The mean $( \pm S D)$ of measured values of $\mathrm{PaCO}_{2}$ were significantly lower in 1st trimester, 2nd trimester \& 3rd trimester of pregnant women than that of non-pregnant women shown in table-II.

On the other hand, the mean $( \pm S D)$ of measured values of $\mathrm{HCO}_{3}{ }^{-}$were 23.61 \pm 2.05 , $21.68 \pm 1.45,21.53 \pm 1.80$ and $21.13 \pm 1.47$ in non-pregnant women and in pregnant women during 1st trimester, 2nd trimester \& 3rd trimester shown in table-III. The mean $( \pm \mathrm{SD})$ of measured values of $\mathrm{HCO}_{3}{ }^{-}$were significantly lower in 1st trimester, 2nd trimester \& 3rd trimester of pregnant women than that of non-pregnant women shown in table-IV.

The $\mathrm{PaCO}_{2}$ \& $\mathrm{HCO}_{3}^{-}$value were gradually decreased during pregnancy from 1st trimester to 3rd trimester than that of non-pregnant women.

There were no statistically significant difference of $\mathrm{PaCO}_{2}$ \& $\mathrm{HCO}_{3}{ }^{-}$in between 1st trimester \& 2nd trimester ; in between 1st trimester \& 3rd trimester ; in between 2nd trimester \& 3rd trimester of pregnant women.

Table $-\mathbf{I}$ : The mean $( \pm$ SD) of measured values of $\mathrm{PaCO}_{2}$ in different groups of subjects.

\begin{tabular}{llc}
\hline Groups & $\mathrm{n}$ & Measured value $(\mathrm{mm} \mathrm{Hg})$ \\
\hline A & 8 & $36.89 \pm 3.70$ \\
B-I & 8 & $32.73 \pm 3.16$ \\
B-II & 8 & $32.46 \pm 3.61$ \\
B-III & 8 & $31.03 \pm 3.20$ \\
\hline
\end{tabular}

J Bangladesh Soc Physiol. 2008 Dec;(3):13-16. 
Table-II: The statistical analysis of mean ( \pm SD) of measured values of $\mathrm{PaCO}_{2}$ in different groups of subjects

Statistical Analysis (measured value)

\begin{tabular}{lc}
\hline Groups & P value \\
\hline A vs B-I & $<0.05^{*}$ \\
A vs B-II & $<0.05^{*}$ \\
A vs B-III & $<0.01^{* *}$ \\
B-I vs B-I & $>0.50^{\text {ns }}$ \\
B-I vs B-III & $>0.10^{\text {ns }}$ \\
B-II vs B-III & $>0.10^{\text {ns }}$ \\
\hline
\end{tabular}

Table -III: The mean $( \pm \mathrm{SD}$ ) of measured values of $\mathrm{HCO}_{3}{ }^{-}$in different groups of subjects.

\begin{tabular}{lcc}
\hline Groups & $\mathrm{N}$ & Measured value $(\mathrm{mm} \mathrm{Hg})$ \\
\hline A & 8 & $23.61 \pm 2.05$ \\
B-I & 8 & $21.68 \pm 1.45$ \\
B-II & 8 & $21.53 \pm 1.80$ \\
B-III & 8 & $21.13 \pm 1.47$ \\
\hline
\end{tabular}

Table - IV: The statistical analysis of mean $( \pm \mathrm{SD})$ of measured values of $\mathrm{HCO}_{3}{ }^{-}$in different groups of subjects

\begin{tabular}{lc}
\multicolumn{2}{c}{ Statistical Analysis (measured value) } \\
\hline Groups & P value \\
\hline A vs B-I & $<0.05^{*}$ \\
A vs B-II & $<0.05^{*}$ \\
A vs B-III & $<0.05^{*}$ \\
B-I vs B-II & $>0.50^{\text {ns }}$ \\
B-I vs B-III & $>0.10^{\text {ns }}$ \\
B-II vs B-III & $>0.50^{\text {ns }}$ \\
\hline
\end{tabular}

A : healthy non-pregnant women (control)

B-I : 1st trimester of pregnant women (experimental)

B-II : 2nd trimester of pregnant women (experimental)

B-III : 3rd trimester of pregnant women (experimental)

n : number of subjects

P values were obtained by unpaired Student's “ $t$ ” test

$*$ = significant

$* * *=$ highly significant

ns $=$ non significant

J Bangladesh Soc Physiol. 2008 Dec;(3):13-16.

\section{Discussion}

In the present study the mean $( \pm S D)$ of measured values of $\mathrm{PaCO}_{2}$ were significantly lower in group 1st trimester, 2nd trimester and 3rd trimester than that of non-pregnant (control) women. Similarly the mean $( \pm S D)$ of measured values of bicarbonate were also significantly lower in group 1st trimester, 2nd trimester and 3rd trimester than that of non-pregnant (control) women. However, both $\mathrm{PaCO}_{2}$ and $\mathrm{HCO}_{3}{ }^{-}$were gradually decreased throughout the pregnancy from 1st to 3rd trimester of pregnant women. Our results are in agreement with other workers ${ }^{3-9}$.

It was noted that $\mathrm{PaCO}_{2}$ and bicarbonate were lower in pregnant women at sea level compared with the non-pregnant (control) women due to maternal ventilation and blood gases undergo substantial changes in pregnancy. There is a $40 \%$ increased in minute ventilation in pregnant women, resulting in decrease of $\mathrm{PaCO}_{2}$ and bicarbonate. This increased ventilation is thought to be mediated by progesterone, which lowers the threshold of respiratory centre and increases the sensitivity the respiratory centre ${ }^{3}$.

It opined that normal pregnancy was associated with a $20 \%$ increase in $\mathrm{O}_{2}$ consumption and a $15 \%$ increase in the maternal metabolic rate. This extra demand is achieved via $40-50 \%$ increase in resting minute ventilation. This hyperventilation causes the $\mathrm{PaCO}_{2}$ and bicarbonate to fall ${ }^{5}$. There is no significant changes of $\mathrm{PaCO}_{2}$ and bicarbonate in pregnant women ${ }^{6}$.

During pregnancy $\mathrm{CO}_{2}$ wash out increases due to hyperventilation, which results of $\mathrm{PaCO}_{2}$ and bicarbonate to falls ${ }^{7-9}$. There is no statistically significant difference in $\mathrm{PaCO}_{2}$ between 1st trimester and 2nd trimester; between 1st trimester and 3rd trimester; between 2nd trimester and 3rd trimester of pregnant women.

\section{Conclusion}

In our study, it may be concluded that $\mathrm{PaCO}_{2}$ and bicarbonate were significantly lower in 1 st 


\section{Article}

trimester, 2nd trimester and 3rd trimester of pregnant women than that of non-pregnant (control) women due to the effect of progesterone causing hyperventilation. Hyperventilation in pregnancy is due to hypersensitivity of respiratory centre. Hyperventilation, expel out $\mathrm{CO}_{2}$ causing decreased $\mathrm{PaCO}_{2}$ and bicarbonate during pregnancy.

\section{Authors Affiliations}

1. * Dr Dipok Kumar Sunyal, Assistant Professor, Department of Physiology, Enam Medical College, Savar, Dhaka, Bangladesh

2. Professor Dr Md Ruhul Amin, Professor and Head, Department of Physiology, Dhaka Medical College, Dhaka, Bangladesh

3. Professor MH Molla, Professor and Head, Department of Physiology, Holy Family Red Crescent Medical College, Dhaka, Bangladesh

4. Professor MA Momen Talukder, Professor and Head, Department of Biochemistry, Sir Salimullah Medical College, Dhaka, Bangladesh

5. Professor Dr Abida Ahmed, Professor and Head, Department of Physiology, Comilla Medical college, Comilla, Bangladesh

6. Dr Momotaj Begum, Assistant Professor, Department of Physiology, Dhaka Medical College, Dhaka, Bangladesh

* For correspondence
Partial pressure of carbon dioxide and bicarbonate

\section{References}

1. DeCherney AH, Pernoll. Maternal physiology during pregnancy. In: Current Obstetrics \& Gynecologic Diagnosis \& Treatment, Lange Medical Books, McGrawHill, New York, Ninth Edition. 2003. pp 159-160.

2. Gee LJB, Packer BS, Millen E. Pulmonary mechanics during pregnancy. Journal of Clinical Investigation. 1967;46(6):945-952.

3. McAuliffe F, Kametas N, Krampl E. Blood gases in pregnancy at sea level and at high altitude. BJOG. 2001;108:980-985.

4. McAuliffe FM, Kametas N, Costello. Respiratory function in singleton \& twin pregnancy. BJOG. An international journal of Obstetrics \& Gynecology. 2002;109:765-769.

5. Piercy C Nelson. Respiratory diseases in pregnancy. Thorax. 2001;56:325-328.

6. Hankins GD, Clark SL, Harvey CJ. Third trimester arterial blood gas and acid base values in normal pregnancy at moderate altitude. Obstet Gynecol 1996;88(3):347-350.

7. Singhal U and Saxena K. Effect of anemia on respiratory and metabolic parameters during third trimester of pregnancy. Indian J Physiol Pharmacol 1987;31(2):130-135.

8. McAuliffe FM, Kametas N, Espirioza J. Respiratory function in pregnancy at sea level and at high altitude. BJOG. 2004 Apr; 111(4):311-315.

9. Rashid BMA, Hussain K, Hussain S. PEFR in relation to phases of pregnancy. Indian J Physiol Pharmacol 2000. 44;(4):511-512. 